\title{
Technological Diagnostics of Human Condition According to Spectral Analysis of Biofield
}

\author{
Evgeniy Bryndin ${ }^{1}$, Irina Bryndina ${ }^{2}$ \\ ${ }^{1}$ Research Center "ESTESTVOINFORMATIKA", Novosibirsk, Russia \\ ${ }^{2}$ Technological Platform "FUTURE MEDICINE", Novosibirsk, Russia
}

Email address:

bryndin15@yandex.ru (E. Bryndin), iriska26@ngs.ru (I. Bryndina)

\section{To cite this article:}

Evgeniy Bryndin, Irina Bryndina. Technological Diagnostics of Human Condition According to Spectral Analysis of Biofield. Advances in Bioscience and Bioengineering. Vol. 7, No. 3, 2019, pp. 50-54. doi: 10.11648/j.abb.20190703.15

Received: June 8, 2019; Accepted: August 1, 2019; Published: August 14, 2019

\begin{abstract}
In article technological diagnostics of mental, physiological and intellectual condition of the person according to the spectral analysis of biofield is considered. The spectral analysis of biofield is fundamentals of natural technology. According to the spectral analysis of biofield the card of a physiological and intellectual condition of the person is formed. According to the card stage-by-stage influence by light, acoustic and electromagnetic radiation on biofield of the person is programmed. Process of correction of biofield is carried out under control of the expert in real time by means of spectroscope. Process of correction comes to an end with normalization of biofield. After normalization of biofield, the person passes to healthy activity. Health of the person most of all depends on a conduct of life. Natural and spiritual processes and a healthy lifestyle help the person and society to be healthy. The family and public culture of a healthy lifestyle and social infrastructure of a health-saving are fundamentals of public health care. Socially infrastructure of transition of the population to a healthy lifestyle matters for formation of healthy human resources of all age and all segments of the population. If the family and public culture of a healthy lifestyle be transferred from generation to generation, then really public health care will be created. In article health saving aspects which promote are considered to become to health care, really, public. The medicine and health system of the future should become health saving up and to conduct the population to healthy longevity.
\end{abstract}

Keywords: Technological Diagnostics, Spectral Analysis, Healthy Lifestyle, Tomography Method

\section{Introduction}

The biofield of the person is tied energetically to functioning of an organism, in general, and its separate bodies and cages, in particular, that is connected with power radiations of bodies and cages of an organism.

The biofield forms a power aura. The luminescence of a biofield is formed by the power centers of the person. The range of energy of biofield contains all information on the person, as present situation and information on states last. Can determine by a luminescence and a form of biofield of state of power centers. It is possible to determine by shine in what state and mood there is a person. Negative impacts on the person also are determined by a luminescence of a biofield. Biofield has 7 working power centers. Each working power centers of biofield is a possession of a certain type of energy and respectively certain tendencies, abilities and opportunities.
Light radiations and mental energy of a biofield allowed stage-by-stage to develop technology of normalization of mental processes and vital activity [1-4].

\section{Mental Energy of Biofield}

Formation of mental energy results from activity of the person in direct interaction with other types of energy: thermal, chemical and electromagnetic. Mental energy is biofield component. Its origin happens in soul of the person, and is reflected by means of various analyzers of a brain. Each analyzer promotes reflection of a concrete power look. The acoustic and visual analyzer is reflected by electromagnetic oscillations. Olfactory and flavoring receptors chemical energy. Skin - kinetic, mechanical and thermal. Vestibular - gravitational.

Having apprehended influence of soul, the brain processes information. Information processing happens under the 
influence of mentality. Synthesis of information happens on the basis of the available experience and knowledge, thinking, attention, memory, ideas of surrounding reality joins. Similar manifestations of mentality have the nonmaterial nature and generate actions. These actions produce allocation of other energy, and have the material nature.

Manifestations of mentality have mental energy. It allocated thoughts, images, emotions, knowledge, feelings, abilities, requirements, moods, motives, desires and habits. Feeling a certain need, the person orders them on importance degree. Requirements can be: physiological, spiritual and material. On this background there is one more source of mental energy - preference. The power of emotion at satisfaction of preferences increases. The person becomes active, strong-willed.

The subjective reality of the individual connected with his feelings about own place in the world around has powerful incentive force. The subjective reality of the person is embodied in the following requirements: self-realization, self-assessment, self-expression, self-affirmation, selfesteem, self-improvement. These requirements form consciousness, the representing information and analytical subsystem of mentality. The consciousness is more active, the mental power message is more powerful. If own selfassessment does not satisfy the person, then he needs selfimprovement. The person seeking for changes of his own life performs the strong-willed operations directed to change of qualities and ability. Self-improvement can be controlled by means of the spectral analysis of biofield.

\section{Definition of Condition of Person According to Spectral Analysis of Biofield}

Energy of biofield it is shown in the form of light and color. Color, its brightness and arrangement of energy indicate physical, emotional, mental and spiritual health of the person. It is possible to visualize color scale of biofield the spectral analysis or photo visualization.

Various colors reflect various qualities of the person and different types of energy of biofield. Colors can be shown in various forms, shades and provisions, including in the form of the color layers which are softly passing each other. To learn to distinguish these shades, time and practice is required. To understand and define value of every color the technique of definition of compliance to it of quality of the person is entered.

Let's consider general information about primary colors in connection with the energy reflected by them. Visualization helps to recognize by flowers of quality, ability and a condition of the person.

Red color of biofield appears at big physical activities, at muscular activity, at physical overfatigue or at negative psychological states: aggression, a condition of a severe stress, a fright or rage, testifies to negative serious condition, to reflection on negative subjects. Red color reflects love inclination, anger, hatred, and its muddy indicates excessive irritation, demonstrating nervousness, irascibility, aggression, impulsiveness or sincere nervousness.

Pink color of biofield is formed by the emotional excitement, a state which is adjusted on communication, an emotional positive state. Pink color is color of mercy, love and purity. It can reflect joy and tranquility and also well developed feeling of solidarity. When at biofield there is pink color, it demonstrates that the person differs in quiet temper, modesty, loves art and all fine. Muddy shades of pink color indicate immaturity and underdevelopment.

Yellow color - color of mind, reasonings, thought processes, focus on any business. Yellow is color of intellectual activity and cheerfulness. Softer shades often tell about the enthusiasm which arose in connection with some vital events about force of imagination and spiritual development (especially transition from light yellow to white). Yellow is color which embodies itself (himself) force of thoughts. More dense and muddy shades of yellow can reflect intensive process of thinking and the analysis and also excessive criticality, feeling of non-recognition and tendency to dogmatism.

Gold yellow color of the restoring power bears health and integrity.

Gold color indicates active spiritual energy and finding of the truth. It reflects the highest energy of love and harmony. More muddy shades of gold indicate that the person for the present is in process of awakening of the highest inspiration.

Green, gently green color of warm experiences, demonstrates that the person takes everything very much to heart - responsibility, commitment, personal experiences, thoughts and care of the family. Green is color of responsiveness and compassion. It reflects development, empathy and tranquility. It is color of friendliness. Muddy or dark shades of green demonstrate indecision and avarice, jealousy and self-love. They point to disbelief in own forces and suspiciousness.

Blue color of mental energy of creativity, positive mental energy. People with blue color possess strong mentality and nervous system, rich imagination and strongly developed figurative thinking.

Blue color demonstrates will of the person. Blue color of tranquility and silence. It reflects devotion, sincerity and gravity. Light shades of blue color speak about active imagination and a good intuition. More dense of tone of blue color point to lifelong search of the Divine, demonstrating religiousness. Bright blue shades indicate honesty and judiciousness. Muddy shades of blue reflect block of perception, timidity, forgetfulness.

Orange color is color of warm warmth, creative creation. He points to courage, joy and sociability. Muddy shades of orange color reflect pride and arrogance and also vanity.

Gray color indicates the movement to disclosure of internal abilities. The shades of gray color close to silvery color reflect inspiration, an intuition and creative imagination. Dark shades of gray color demonstrate reserve of the person and about his belonging to type of so-called 
lone wolves.

Brown color shows desire to be improved, and about such qualities, as diligence and systemacity.

Black is color of protection. It is color which specifies that the person has secrets.

Violet color testifies to high degree of an intuition, ability to use spiritual energy. Violet color of association of heart and reason, physical and spiritual. It reflects independence and an intuition and also indicates the dynamic and well developed imagination. It is the sign of the person who is in search. Purple shades demonstrate ability is realistic and prudently to treat affairs. More pale and light tone of violet and purple color point out humility and spirituality. More dark and muddy shades signal about tendency to superiority over others, indicate the need for sympathy and experiences concerning misunderstanding from other people.

The white sparkling color demonstrates sanctity of the person. White color reflects the truth and purity. He points to what energy of the person is capable to clean and improve. Besides, it testifies to creative potential.

These are the primary colors, speaking about work of the power centers and a condition of biofield of the person. Actually shades of flowers of energy of biofield and options of their set huge set. To understand what happens to the person what power prevails whether the power centers correctly work, it is necessary to carry out the spectral analysis of biofield of the person. The biofield is necessary to keep clean.

The clean equilibrium biofield of the person characterizes the following human qualities. Self-criticism identification of mistakes and shortcomings of, analysis and assessment of negative sides in the activity, the thinking and behavior. Justice - execution due: it is right duties, work for remuneration, punishment for crime, etc. Sincerity - lack of contradictions between real intentions and words. Keenness ability to feel emotional both state of mind of other person and ability to help it. Truthfulness - spiritually moral commitment to the truth, fact, reality, reality. Politeness ability validly and tactfully to communicate with people. Honesty - fidelity to the assumed obligations, sincerity before others and before by itself concerning those motivations by which the person is guided. The white sparkling color of biofield demonstrates sanctity of the person.

\section{Normalization of Biofield}

Any violation in physical structure of the person is preceded and followed by violation in biofield of the person. Impact by the light, acoustic and power field on biofield allows to normalize it. The biofield bears adaptation function. The analog reconstructive optical method of wave normalization of the power centers restores balance of their energy. Light, acoustic and power impact on biofield normalizes it, and it is adaptive is harmonized. At impact on a biofield of the person there is a strong power reorganization. Color and saturation of flowers of biofield change. When passing optical radiation through biological fabric absorption it is played a major role. By means of optical analog reconstructive tomographs step by step adjust the structure of biofield with high spatial resolution.

The biofield is normalized the reconstructed laser light sources which radiate lengths of waves in all visible range of a range, such as C-WAVE and NT252. The reconstructed laser light source of C-WAVE from the Hubner-Photonics company generates continuous $(\mathrm{CW})$ radiation in the visible range of lengths of waves of 450-650 nanometers. The compact reconstructed nanosecond NT252 laser of EKSPLA. Its module of the parametrical generator of light allows to reconstruct automatically wavelength in the visible range of 335-2600 nanometers. In biofield light laser radiation dissipates and affects optical not uniformity of an organism and is absorbed by the power centers. Restoration of biofield is carried out step by step by selection of light radiation by comparison with a sample. The biofield completely restores color harmony (Figure 1).

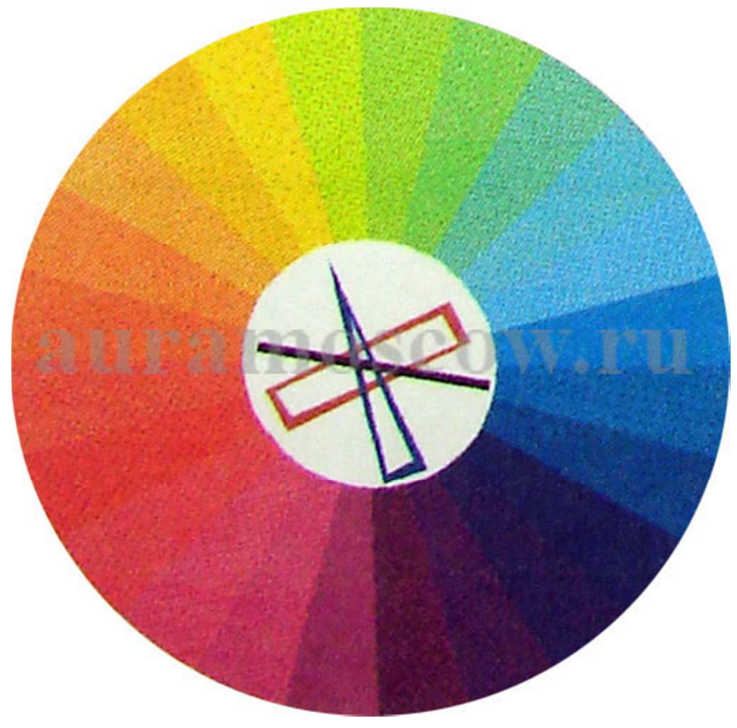

Figure 1. Color visualization of harmony of human biofield.

The power centers of biofield radiate quanta of light of various wavelength, which are registered spectral devices the devices which are visually representing the turned-out light range. Spectral devices serve as well as a dividing element of a system of spectroscopy because the light stream is summarized from all power centers, and its tasks include division of the general massif of light into ranges of the separate power centers and determination of their intensity which allows to draw conclusions about the size of the present energy [5-6].

Spectroscopes do available viewing of a range for direct observation by the person via special telescopes. Direct viewing allows to conduct correction of wave impact by the thermal, sound, light and power field on biofield towards its normalization.

The round shape shows balance of energy or the power center. Not round, vague images note an imbalance of the power center. Oval: easy imbalance. Big: high power activity. Small: low energy of activity. Bright: it is balanced, with 
high energy. Dark: low energy, imbalance.

The disharmony of power system demands power balancing. Well balanced power centers are in harmony.

By analog reconstructive optical method of a tomography it is possible to normalize a biofield and to support him in the balanced state.

Positive people who lead a healthy lifestyle are not ill and the frequency of vibrations of their power field was equal 8 hertz. It is frequency Schuman's resonator under the influence of which there is all wildlife.

Health to the person is provided by the clean nature and spiritual and naturalistic practice of a healthy lifestyle [7-15].

\section{Technique of Transition to a Healthy Lifestyle}

Transition to a healthy lifestyle is carried out in four stages of formation of useful habits.

Stage 1. Formation of useful habits of maintenance of hygienic and endoecological purity of an organism. Habits are formed on performance of hygiene and endoecology. The clean environment of an organism and cages is one of necessary conditions of a wave resonance of cages. Purity guarantee of health.

Stage 2. Development of useful habits of achievement of spiritual, and power purity and healthy state. Spiritual and power purity are necessary conditions of a wave resonance of cages.

Stage 3. Acquisition of useful habits health of saving for preservation of a healthy state.

Stage 4. Accumulation of experience of preservation of a healthy state useful habits within a year. Accumulation of experience is carried out by useful habits health of saving in various house, social and natural seasonal conditions (in the spring, in the summer, in the fall and in the winter).

\section{Biodiagnostics of Mentality on Basis of GRV Method}

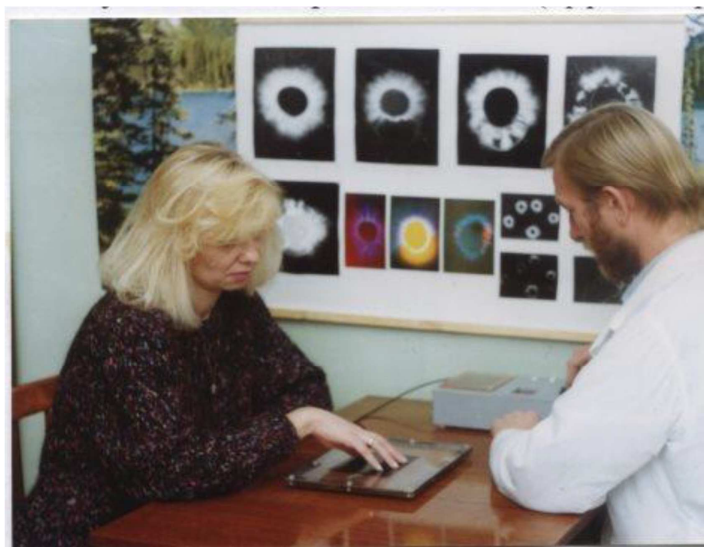

Figure 2. Biodiagnostics.

On basis of GRV method - it is possible for gas-discharge visualization of radiations of biofield of the person (by the Kirlian method) quickly and with high precision to find changes of field structures and potentials of power radiations of biological bodies (Figure 2). What allows to diagnose effectively mentality of the person.

Researchers on physical medicine noticed long ago that positive people who lead a healthy lifestyle are not ill when the frequency of vibrations of their power field was included into a resonance with a frequency of vibrations of 8 hertz.

Destructive radiations appear at the person as a result of action of its negative spiritual qualities or emotions: * the grief gives vibrations - from 0.1 to 2 hertz; * fear from 0.2 to 2.2 hertz; * offense - from 0.6 to 3.3 hertz; * irritation from 0.9 to 3.8 hertz; * indignation - from 0.6 to 1.9 hertz; * the egoism - gives vibrations of at most 2.8 hertz; * irascibility (irascibility) - 0.9 hertz; * flash of rage -0.5 hertz; anger - 1.4 hertz; * arrogance -0.8 hertz; pride 3.1 hertz; * neglect - 1.5 hertz; * superiority - 1.9 hertz; * pity -3 hertz.

\section{Conclusion}

The new direction of health care providing healthy longevity is formed on the basis of spiritual and naturalistic approach, normalization of a biofield by analog reconstructive optical method of a tomography and a healthy lifestyle of the person [15]. Biodiagnostics of power channels of biofield of the person and a photo visualization of biofield help any person:

(1) it is better to understand the inner world, features of a warehouse of the personality;

(2) to notice dependence of the health on psychological emotional state;

(3) to see the impact which had by external factors on a physical, sincere and power state;

(4) to learn to control the psychological emotional state, to smooth consequences of external influences, to choose optimal solutions in difficult or responsible situations;

(5) to estimate how outside world and its influences influence vigorous activity.

\section{References}

[1] Bryndin E. G. Psychological and Social Aspects Formations of Thinking, Consciousness and Behavior. SM Physical Medicine \& Rehabilitation. Volume 2 Issue 1 2018. P. 1-5.

[2] Bryndin E. G., Bryndina I. E. Normalization of Psyche by Healthy Lifestyle of Various Groups of the Population. American Journal of Applied Psychology. Volume 6, Issue 4, 2017, Pages: 51-56.

[3] Evgeniy Bryndin. Satisfaction with valuable realization of requirements by spiritual personality counterbalances psyche. MOJ Public Health. 2018; 7 (6): 254-257.

[4] Bryndin E. G. Putmakov A. N. Aspects of spectral analysis of biofield. Biomedical Journal of Scientific \& Technical Research 16 (2)-2019. Pages: 1-3. 
[5] Bryndin E. G. Putmakov A. N. Frequency color visualization of a condition of the person according to spectral analysis of biofield and biodiagnostics. Journal of Medical Practice and Review. 3 (4)-2019. Pages: 505-509.

[6] Bryndin E. G., Bryndina I. E. Natural Measures of Normalization of Vital Systems of the Person for Maintaining of the Healthy State. Journal of Health Research. Volume 1. 2017. Pages 25-38.

[7] Bryndin E. G., Bryndina I. E. Healthy Wellbeing of the Person and Society. Journal "The European Proceedings of Social \& Behavioural Sciences EpSBS". Volume XIX. 2017. Pages 130-139.

[8] E. G. Bryndin, I. E. Bryndina. Sanatorium Rehabilitation of the Population by the Healthy Lifestyle. International journal "Rehabilitation Sciences", Volume 2, Issue 2. 2017. P. 35-40.

[9] Bryndin E. G., Bryndina I. E. Natural Technology of High Quality Transition to Healthy Activity. J. Galore International Journal of Health Sciences and Research. V. 3, Issue 1. 2018. P. 24-32.

[10] Evgeniy Bryndin, Irina Bryndina. Natural and Spiritual
Aspects of Health and Social Infrastructure of Public Health Care on Base of Healthy Lifestyle. Medical Open Journal Gerontology \& Geriatrics. Volume 3 Issue 6. 2018. P. 404408.

[11] Evgeniy Bryndin, Irina Bryndina. Adaptive Ecological Social Technology of High Quality Transition to Healthy Long Activity. Research and Reviews on Healthcare: Open Access Journal (RRHOAJ). 3 (1). 2018. P. 226-232.

[12] Bryndin E. G., Bryndina I. E. Hygiene and Endoecology, Light Bioenergy and Natural Ecology, Balanced Mentality and Spiritual Life as Criterion of Health. Innovative Journal of Medical and Health Science. Vol 9, Issue 2, 299-306. 2019.

[13] Evgeniy Bryndin, Irina Bryndina. Development of Health Care on Basis of Healthy Lifestyle for Forming Future Medicine of Longevity. Acta Scientific Medical Sciences. Vol. 3, Issue 5 (2019): 35-41.

[14] Bryndin Evgeniy Grigorevich, Bryndina Irina Evgenievna. International Public Health Care on Basis Healthy Lifestyle. Asian Journal of Medical Science Research \& Review, Volume 1, Issue 2. 2019. Pages: 88-96. 